\title{
PENGARUH TERAPI BERMAIN (TEKNIK BERCERITA) TERHADAP DAMPAK HOSPITALISASI PADA ANAK USIA PRA SEKOLAH DI IRINA E RSUP. PROF. DR. R. D. KANDOU MANADO
}

\author{
Finni Fitria Tumiwa ${ }^{1}$ \\ ${ }^{1}$ Staff Dosen Program Studi Ilmu Keperawatan Fakultas Kesehatan Institut Kesehatan dan Teknologi \\ Graha Medika Kotamobagu \\ Alamat Korespondensi: finnitumiwa@stikesgrahamedika.ac.id
}

\begin{abstract}
Abstrak
Hospitalisasi merupakan suatu keadaan krisis pada anak, saat anak sakit dan dirawat di rumah sakit, keadaan ini terjadi karena anak berusaha untuk beradaptasi dengan lingkungan asing dan baru yaitu rumah sakit, sehingga kondisi tersebut menjadi faktor stressor bagi anak baik terhadap anak maupun orang tua dan keluarganya. Tujuan penelitian ini adalah untuk mengetahui pengaruh terapi bermain (teknik bercerita) terhadap dampak hospitalisasi pada anak usia pra sekolah di IRINA E RSUP Prof. Dr. R. D. Kandou Manado. Penelitian ini menggunakan jenis penelitian kuantitatif dengan desain penelitian one group pre test-post test design. Populasi adalah seluruh pasien anak usia pra sekolah yang dirawat di IRINA E RSUP Prof. Dr. R. D. Kandou Manado yang bejumlah 16 orang. Sampel yang digunakan dalam penelitian adalah total populasi. Data yang diperoleh kemudian ditabulasi dan disajikan dalam bentuk tabel distribusi frekuensi, kemudian dianalisis melalui uji statistik uji-T. Hasil analisis penelitian ini menunjukkan terdapat hubungan yang signifikan antara terapi bermain dengan dampak hospitalisasi pada anak usia pra sekolah yang dirawat di IRINA E RSUP. Prof. Dr. R. D. Kandou Manado, dimana diperoleh nilai $p=0,000<0,05$. Kesimpulan pada penelitian ini yaitu terdapat hubungan yang signifikan antara terapi bermain dengan dampak hospitalisasi pada anak usia pra sekolah yang dirawat di IRINA E RSUP. Prof. Dr. R. D. Kandou Manado. Saran bagi perawat diharapkan hendaknya dapat mengaplikasikan terapi-terapi sederhana yang diberikan kepada anak usia prasekolah untuk mengurangi dampak hospitalisasi.
\end{abstract}

Kata Kunci: Terapi Bermain, Dampak Hospitalisasi.

\begin{abstract}
Hospitalization is a crisis situation in children, when the child is sick and must be taking care in hospital, this situation occurs because the child tries to adapt to a new and foreign environment, namely the hospital, so that this condition becomes a stressor factor for the child, both the child and the parents and their family. This study aimed to investigate the effect of the play therapy (storytelling technnique) to the hospitalization effects on pre-school age children at IRINA E RSUP. Prof. Dr. R. D. Kandou Manado. This research uses quantitative research with one group pre-test-post-test design. The population was all pre-school age children who were treated at IRINA E RSUP. Prof. Dr. R. D. Kandou Manado. Total sampling was used to recruit 16 pre-school age children. The data obtained were then tabulated and presented in the form of a frequency distribution table, then analyzed through the T-test statistical test. The results of the analysis of this study is indicate that there is a significant relationship between play therapy and the hospitalization effects on pre-school age children who are treated at IRINA E RSUP. Prof. Dr. R. D. Kandou Manado, where the $p$-value $=0.000<0.05$ was obtained. In conclusion, there is a strong and positive correlation between play therapy and the hospitalization effects on pre-school age children who are treated at IRINA E RSUP. Prof. Dr. R. D. Kandou Manado. Based on the result of this study, it is suggested for nurses are expected to be able to apply simple therapies given to preschool children to reduce the impact of hospitalization.
\end{abstract}

Keywords: Play Therapy, Hospitalization Impact 


\section{PENDAHULUAN}

Hospitalisasi merupakan suatu keadaan krisis pada anak, saat anak sakit dan dirawat di rumah sakit, keadaan ini terjadi karena anak berusaha untuk beradaptasi dengan lingkungan asing dan baru yaitu rumah sakit, sehingga kondisi tersebut menjadi faktor stressor bagi anak baik terhadap anak maupun orang tua dan keluarganya (Ema 2012).

Hospitalisasi menjadi suatu proses karena suatu alasan yang berencana atau darurat, mengharuskan anak tinggal di rumah sakit, menjalani terapi dan perawatan sampai pemulangan kembali ke rumah dan hospitalisasi dapat menimbulkan kecemasan.

Kecemasan merupakan respon individu terhadap suatu keadaan yang tidak menyenangkan dan dialami oleh semua makhluk hidup sehari-hari, pada kanak-kanak (toddler) yang belum mampu berkomunikasi dengan menggunakan bahasa yang memadai dan pengertian terhadap realita terbatas. Selain itu, lingkungan yang belum dikenal akan mengakibatkan perasaan tidak aman dan cemas (Rekawati dkk, 2013)

Sakit merupakan pengalaman yang tidak menyenangkan bagi anak. Reaksi anak dan keluarganya terhadap sakit dan rumah sakit adalah dalam bentuk kecemasan, stress dan perubahan perilaku. Reaksi anak usia sekolah ketika mengalami perawatan di rumah sakit adalah dengan menunjukan reaksi perilaku seperti protes, putus asa dan regresi (Wong, 2011).

Sakit dan dirawat di rumah sakit merupakan krisis yang utama tampak pada anak. Anak yang dirawat di rumah sakit mudah mengalami krisis sebab anak mengalami perubahan, baik terhadap status kesehatan maupun lingkungannya dari kebiasaan seharihari, anak mempunyai sejumlah keterbatasan dalam mekanisme koping untuk mengatasi masalah kejadiankejadian yang bersifat menekan. Reaksi anak dalam mengatasi krisis tersebut dipengaruhi oleh tingkat usia, pengalaman sebelumnya terhadap sakit dan dirawat di rumah sakit, sistem pendukung yang tersedia, serta ketrampilan koping dalam menanangani stress (Rekawati dkk, 2013).

Peran perawat dalam meminimalisir stres akibat rawat inap pada anak sangatlah penting yaitu cukup dengan menentukan dampak hospitalisasi selama berinteraksi dengan anak, melalui pemberian asuhan keperawatan yang komperhensif. Salah satu upaya yang dapat dilakukan perawat untuk mengurangi kecemasan pada anak yang dirawat adalah dengan terapi bermain (Rekawati dkk, 2013).

Menurut survey tahun 2001 hampir 4.000.000 anak di Amerika Serikat dalam satu tahun mengalami hospitalisasi yang lama. Hal ini terjadi karena adanya traumatik dan stress yang dialami oleh anak. Di Indonesia setiap tahun terdapat lebih dari 5.000.000 anak yang menjalani masa perawatan yang lama di rumah sakit (Cherty dan Kozak, 2001 dalam Dian, 2011).

Berdasarkan survey awal di Instalasi Rawat Inap (IRINA) E RSUP. Prof. Dr. R. D. Kandou Manado, terdapat 45 pasien anak usia pra sekolah yang di rawat selama bulan Desember sampai Februari 2018, dengan BOR (Bed Occupancy Rate) $80 \%$ dan ALOS 7-9 hari. Observasi awal menunjukkan ratarata pasien anak usia pra sekolah mengalami tingkat kecemasan ringan sampai berat sebagai dampak hospitalisasi yang lama.

Lingkungan sekitar yang membuat pasien anak tidak nyaman, keberadaan orang-orang asing, obat-obatan dan alatalat yang terasa asing, pembatasan aktivitas, jauh dari teman sepermainan 
karena hospitalisasi membuat pasien anak semakin takut dan cemas. Dampak dari hospitalisasi di IRINA E yaitu, pasien anak sering menolak untuk makan, sering bertanya, sering menangis perlahan, meminta untuk pulang ke rumah dan tidak kooperatif terhadap petugas kesehatan.

Berdasarkan uraian diatas maka penulis tertarik untuk meneliti tentang pengaruh terapi bermain (teknik bercerita) terhadap dampak hospitalisasi pada anak usia prasekolah di IRINA E RSUP. Prof. Dr. R. D. Kandou Manado. Tujuan dari penelitian ini yaitu untuk mengetahui pengaruh terapi bermain (teknik bercerita) terhadap dampak hospitalisasi pada anak usia prasekolah di IRINA E RSUP. Prof. Dr. R. D. Kandou Manado

\section{METODE PENELITIAN}

Penelitian ini bersifat kuantitatif dengan jenis penelitian quasi experimental dan menggunakan metode Pre test - Post test Design. Penelitian yang dilakukan hanya pada satu kelompok tanpa ada kelompok pembanding, sehingga setiap subjek merupakan kelas kontrol untuk dirinya sendiri. Penelitian dilaksanakan di IRINA E RSUP. Prof. Dr. R.D. Kandou Manado pada bulan Juli-Agustus 2018. Populasi pada penelitian ini adalah anak usia pra sekolah yang baru dirawat di IRINA E RSUP. Prof. Dr. R.D. Kandou Manado yang berjumlah 16 responden. Teknik pengambilan sampel menggunakan teknik total sampling (mengambil seluruh total populasi untuk dijadikan sampel penelitian) yang berjumlah 16 orang anak usia pra sekolah.

Alat ukur menggunakan lembar observasi dengan Panduan pelaksanaan terapi bermain: teknik bercerita dan observasi dampak hospitalisasi pada anak dengan menggunakan skala kecemasan anak (preschool anxiety scale: parent report) by Susan H. Spence and Ronald Rapee (1999).

Pengumpulan data dilakukan dengan mengisi lembar observasi berdasarkan SOP teknik bermain pada anak; teknik bercerita, setelah itu dilanjutkan dengan pengisian lembar observasi menggunakan PAS (preschool anxiety scale: parent report) dari orang tua dengan estimasi waktu 15-30 menit. Data yang terkumpul kemudian ditabulasi ke dalam matriks pengumpulan data yang telah dibuat sebelumnya oleh peneliti dan kemudian dilakukan analisa data.

Uji korelasi yang digunakan dalam penelitian ini yaitu uji $T$. Data yang digunakan dalam penelitian ini telah berdistribusi normal. Hal ini dibuktikan dengan grafik histogram dan kurva berbentuk lonceng (Bell Shape). Nilai Skewness dibagi dengan standar error menghasilkan angka $\leq 2(0,74)$, yang berarti distribusi data normal. Penelitian ini telah mendapatkan surat keterangan laik etik dari Komisi Etik Penelitian RSUP Prof. Dr. R.D. Kandou Manado.

\section{HASIL PENELITIAN}

Tabel 1 .

Karakteristik Responden Penelitian

\begin{tabular}{llll}
\hline Variabel & Katagori & $\mathbf{n}$ & \% \\
\hline Usia & 3 tahun & 1 & 6,3 \\
& 3,5 tahun & 11 & 68,8 \\
& 4 tahun & 3 & 18,8 \\
& 4,5 tahun & 1 & 6,3 \\
\hline Jenis & Laki-laki & 10 & 62,5 \\
Kelamin & Perempuan & 6 & 37,5 \\
\hline
\end{tabular}


Tabel 1 menunjukkan karakteristik responden penelitian anak usia pra sekolah dengan kelompok umur 3 tahun berjumlah 1 orang $(6,3 \%)$, umur 3,5 tahun berjumlah 11 orang anak $(68,8 \%)$, umur 4 tahun berjumlah 3 orang $(18,8 \%)$ dan umur 4,5 tahun berjumlah 1 orang $(6,3 \%)$ dari total 16 responden.
Berdasarkan tabel 1 , jenis kelamin lakilaki merupakan responden terbanyak dengan jumlah responden 10 orang atau sekitar $62,6 \%$ dari total responden. Di urutan kedua responden dengan jenis kelamin perempuan dengan jumlah 6 orang responden atau sekitar $37,5 \%$ dari total 16 responden.

Tabel 2.

Frekuensi Tingkat Kecemasan Sebelum Dilakukan Terapi Bermain

\begin{tabular}{lcc}
\hline \multicolumn{1}{c}{ Tingkat Kecemasan } & $\mathbf{n}$ & \% \\
\hline Cemas Ringan & 5 & 31,2 \\
Cemas Sedang & 10 & 62,5 \\
\hline Cemas Berat & 1 & 6,3 \\
\hline Total & $\mathbf{1 6}$ & $\mathbf{1 0 0}$ \\
\hline
\end{tabular}

Tabel 2 menunjukkan bahwa sebelum dilakukan terapi bermain pada anak usia pra sekolah di IRINA E RSUP Prof. Dr. R. D. Kandou Manado, pada umumnya tingkat kecemasan anak usia prasekolah berada pada tingkat kecemasan sedang sebanyak 10 responden $(62,5 \%)$, cemas ringan sebanyak 5 responden $(31,2 \%)$, cemas berat 1 responden $(6,3 \%)$ dari total 16 responden.

Tabel 3.

Frekuensi Tingkat Kecemasan Setelah Dilakukan Terapi Bermain

\begin{tabular}{lcc}
\hline \multicolumn{1}{c}{ Tingkat Kecemasan } & n & \% \\
\hline Cemas Ringan & 14 & 87,5 \\
Cemas Sedang & 2 & 12,5 \\
\hline Total & $\mathbf{1 6}$ & $\mathbf{1 0 0}$ \\
\hline
\end{tabular}

Tabel 3 menunjukkan menunjukkan bahwa setelah dilakukan terapi bermain, tingkat kecemasan responden pada umumnya berada pada tingkat kecemasan ringan. Sebanyak 14 responden memiliki tingkat kecemasan ringan $(87,5 \%)$. Sementara responden dengan tingkat kecemasan sedang sebanyak 2 orang $(12,5 \%)$ dari total 16 responden.

Tabel 4 Hasil Analisis $U j i-T$

\begin{tabular}{ccccccc}
\hline Variabel & Mean & SD & Min & Max & $p$ value & $\mathrm{N}$ \\
\hline Terapi bermain & & & & & & \\
Sebelum & 23,1 & 4,7 & 14 & 28 & 0,000 & 16 \\
Sesudah & 12,9 & 1,8 & 10 & 16 & &
\end{tabular}

Tabel 4 menunjukkan bahwa rata-rata penilaian tingkat kecemasan pada anak usia pra sekolah sebelum dilakukan terapi bermain berjumlah 23,1 atau berada pada tingkat kecemasan sedang dengan standar deviasi 4,7. Pada penilaian kedua yakni setelah selesai dilakukan terapi bermain pada anak usia pra sekolah didapat rata-rata perolehan penilaian tingkat kecemasan berjumlah 12,9 atau berada pada tingkat 
kecemasan ringan dengan standar deviasi 1,8 .

\section{PEMBAHASAN}

Berdasarkan hasil penelitian ini menunjukkan bahwa dampak hospitalisasi pada anak di IRINA E RSUP. Prof. Dr. R.D.Kandou Manado pada umumnya ringan. Hal ini ditunjukkan dengan perolehan hasil bahwa sebanyak $65,6 \%$ penilaian orang tua bahwa dampak yang ditimbulkan akibat hospitalisasi berada pada kategori ringan, walaupun beberapa orang tua menilai dampak hospitalisasi berada pada kategori berat.

Dampak hospitalisasi pada anak usia prasekolah di IRINA E RSUP. Prof. Dr. R.D.Kandou Manado masih tergolong ringan dikarenakan saat anak ditinggalkan oleh orang tua anak tidak menangis, anak mau menjawab pertanyaan perawat, anak mau ditemani atau ditolong oleh orang lain selain orang tuanya sendiri, anak berminat untuk bermain dan mau minum obat dan makan walaupun ibu ada didekatnya.

Berdasarkan hasil penelitian terhadap 16 responden yang merupakan orang tua dari anak usia prasekolah di IRINA E RSUP. Prof. Dr. R.D. Kandou Manado diperoleh hasil bahwa terdapat pengaruh antara terapi bermain dengan dampak hospitalisasi pada anak usia prasekolah. Hal ini dibuktikan dengan perolehan nilai $p$ dari hasil uji statistika dengan menggunakan uji $T$ diperoleh nilai $p$ sebesar 0,000 . Nilai yang lebih kecil dari nilai alpha $(0,05)$ yang berarti terdapat pengaruh terapi bermain dengan dampak hospitalisasi pada anak usia prasekolah di IRINA E RSUP. Prof. Dr. R.D.Kandou Manado.

Hasil penelitian membuktikan bahwa terdapat pengaruh antara terapi bermain dengan dampak hospitalisasi pada anak usia prasekolah di IRINA E RSUP. Prof. Dr. R.D. Kandou Manado dikarenakan peran perawat dalam memberikan terapi bermain melalui teknik bercerita sehingga menurunkan tingkat kecemasan pada anak. Hal ini dibuktikan dengan peran perawat yang memberikan dukungan perawatan dalam upaya penyembuhan pada anak, memberikan motivasi kepada anak berupa hadiah dan pujian jika anak menerima dan mengikuti terapi bermain dengan baik.

Kondisi anak yang dirawat di rumah sakit saat ini banyak mengalami masalah yang lebih serius dan kompleks dibandingkan kejadian hospitalisasi pada tahun-tahun sebelumnya. Timbul tantangan-tantangan yang harus dihadapi anak, seperti mengatasi suatu perpisahan, penyesuaian dengan lingkungan yang asing baginya penyesuaian dengan banyak orang yang mengurusnya, dan kerap kali harus berpengaruh dan bergaul dengan anakanak lain yang sakit serta pengalaman mengikuti terapi yang menyakitkan.

Hasil penelitian ini juga sejalan dengan penelitian yang dilakukan oleh Utami (2014) yang meneliti tentang dampak hopitalisasi terhadap perkembangan kesehatan anak di rumah sakit menyatakan bahwa terdapat pengaruh antara peran orang tua terhadap dampak hospitalisasi di rumah sakit. Peran keluarga atau dalam hal ini orang tua sangat diperlukan bagi proses kesembuhan anak karena tidak cukup hanya peran perawat saja tetapi peran orang tua.

Penelitian ini sejalan dengan penelitian yang dilakukan oleh Kurniawati (2011) dimana ada pengaruh terapi bermain terhadap respon perilaku dari anak pra sekolah yang mengalami hospitalisasi dimana diperoleh nilai signifikansi $\mathrm{p}=0,004$.

Penelitian yang dilakukan oleh Handayani dan Puspitasari (2008) 
menunjukkan hasil yang signifikan antara pengaruh anak yang sebelum dan sesudah diberikan terapi bermain dalam konteks terhadap perilaku kooperatif selama menjalani perawatan di rumah sakit.

Menurut Supartini (2004), terapi bermain merupakan terapi pada anak yang menjalani hospitalisasi. Pada saat dirawat di rumah sakit, anak akan mengalami berbagai perasaan tidak menyenangkan, seperti marah, takut, cemas dan nyeri. Dengan melakukan permainan anak akan terlepas dari ketegangan dan stress yang dialaminya karena dengan melakukan permainan, anak akan dapat mengalihkan rasa sakitnya pada permainannya dan relaksasi melalui kesenangannya melakukan permainan. Bermain tidak dapat dipisahkan dari kehidupan anak, karena bermain sangat diperlukan untuk perkembangan anak. Bermain dapat digunakan sebagai media psiko terapi atau pengobatan terhadap anak yang dikenal dengan sebutan Terapi Bermain. Karena pada saat dirawat di rumah sakit, anak akan mengalami berbagai perasaan yang sangat tidak menyenangkan seperti cemas. Adapun tujuan bermain bagi anak di rumah sakit yaitu, mengurangi perasaan takut, cemas, sedih, tegang dan nyeri.

Berdasarkan pada penelitian serta teori yang telah dilakukan menunjukkan bahwa pentingnya terapi bermain bagi penurunan terhadap reaksi hospitalisasi dari anak yang dalam penelitian ini umunya terdapat pada anak pra sekolah yaitu anak balita. Adapun reaksi-reaksi yang ditemui dalam penelitian yaitu anak umumnya merasa ketakutan jika harus berada jauh dari orang tua sehingga orang tua harus senantiasa berada disamping anak, anak menolak untuk diberikan tindakan pengobatan dari perawat dengan cara menangis, menjerit dan melakukan perlawanan dalam hal penolakan kepada perawat, anak selalu saja menangis karena takut dan cemas, disamping itu anak akan menyatakan permintaannya untuk segera pulang ke rumah. Hal-hal tersebut merupakan serangkaian reaksi yang biasa ditemui pada anak yang mengalami hospitalisasi.

\section{KESIMPULAN DAN SARAN}

Kesimpulan penelitian ini ada 3 hal, yaitu; 1) Terapi bermain pada anak usia prasekolah di IRINA E RSUP. Prof. Dr. R.D. Kandou Manado pada umumnya baik; 2) Dampak hospitalisasi pada anak usia prasekolah di IRINA E RSUP. Prof. Dr. R.D. Kandou Manado pada umumnya ringan; 3) Terdapat pengaruh terapi bermain dengan dampak hospitalisasi pada anak usia prasekolah di di IRINA E RSUP. Prof. Dr. R.D. Kandou Manado.

Saran untuk penelitian ini yaitu: 1) Untuk pimpinan di IRINA E RSUP. Prof. Dr. R.D.Kandou Manado agar lebih melibatkan orang tua dalam melakukan tindakan perawatan pada anak prasekolah yang dirawat; 2) Untuk orang tua agar lebih memberikan peran lebih bagi anak yang dirawat di rumah sakit agar membantu proses penyembuhan penyakitnya; 3) Untuk pendidikan keperawatan kiranya hasil penelitian ini dijadikan referensi bagi bidang pendidikan agar lebih memperhatikan masalah peran orang tua dalam merawat anak guna mengurangi dampak hospitalisasi.

\section{DAFTAR PUSTAKA}

Agustina, R. (2016). Pengaruh Terapi Bermain Play Dough Terhadap Perkembangan Kreativitas Anak Usia Pra sekolah, Skripsi, Prodi S1 Keperawatan STIKes Insan Cendekia Medika, Jombang.

Apriani, D. (2013). Hubungan Antara Hospitalisasi Anak Dengan Tingkat 
Kecemasan Orang Tua. Jurnal Keperawatan Soedirman. Volume 8. PSIK STIK Jendral Achmad Yani Cimahi. (Online). (keperawatan.unsoed.ac.id/sites/default /files /jks20130802_92-104.pdf

Aini, A. P. (2016). Pengaruh Terapi Bermain Walkie Talkie Terhadap Tingkat Kecemasan Akibat Hospitalisasi pada Anak Usia Prasekolah di RSUD. Dr. Moerwadi

Arikunto., (2010). Prosedur Penelitian, EGC: Jakarta.

Dewi, P. P., \& Sufriani. (2017). Pengetahuan, Sikap dan Tindakan Perawat Dengan Tingkat Kecemasan Hospitalisasi Anak Prasekolah.

Fradianto, I. (2014). Pengaruh Terapi Bermain Lilin Terhadap Penurunan Tingkat Kecemasan Pada Anak Usia Prasekolah yang Mengalami Hospitalisasi Di RSUD Dr. Soedarso Pontianak. Jurnal Publikasi volume 1 No. 1. Program studi Keperawatan Fakultas Kedokteran Universitas Tanjungpura Pontianak. (Online).

(http://jurnal.untan.ac.id/index.php/jmk epe rawatanFK/article/view/5274,

Gustina. (2011). Pengaruh permainan modifikasi terhadap perkembangan motoric kasar dan halus anak di TK Kartika.

Hasnita,E., \& Gusvianti, S. (2018). Meningkatkan Kooperatif Selama Menjalani Perawatan Pada Anak Usia Prasekolah (3-5 tahun) Melalui Terapi Bermain.

Hutabarat, M., Herman., \& Nurfiarti.,A. (2017). Analisa Persepsi Perawat Tentang Pelaksanaan Terapi Bermain pada Anak yang Mengalami Hospitalisasi di RSUD dr. Abdul Aziz Singkawang: Studi Fenomenologi.

Harjaningrum, A. T. (2007). Peranan Orang Tua dan Praktisi Dalam Membantu Tumbuh Kembang Anak Berbakat Melalui Pemahaman Teori dan Tren Pendidikan. Jakarta: Prenada
Hawari. (2006). Pendekatan Holistik Pada Gangguan Jiwa Skizofrenia. Jakarta : Gaya Baru.

Hidayat. (2005). Anak Usia Prasekolah. Edisi 1, Jakarta: Salemba Medika.

Iwang, D. (2008). Stress Pada Anak. Jakarta: Gramedia.

Kartono, K. (2007). Perkembangan Psikologi Anak. Jakarta: Erlangga.

Kristension, I. (2012). Dukungan Orang Tua Pada Anak Yang Dihospitalisasi.

Laili, I. E. (2006), Faktor-faktor yang Mempengaruhi Kecemasan Pada Anak Sekolah Yang di Rawat di Instalasi Kesehatan Anak (INSKA) RSUP Dr.Sardjito Yogyakarta, Skripsi, FK UGM,

Yogyakarta.https://www.scribd.com/do c/194479245/ Faktor-YangMempengaruhi Kecemasan-AnakSekolah. .

Paturuhu, A. R. (2014). Pengaruh Terapi bermainTerhadap Dampak Hospitalisasi Pada Anak Usia Prasekolah Eka Hospital Bsd Tangerang. Jurnal Keperawatan Universitas Esa Unggul Jakarta. Halaman 1-9. http://digilib.esaunggul.ac.id/public/UE U-Undergraduate-3031-Lampiran.pdf.

Soetjiningsih dan Ranuh., (2013). Tumbuh Kembang Anak, edisi II. Jakarta: Penerbit Buku Kedokteran EGC

Utami, Y. (2014). Dampak Hospitalisasi Terhadap Perkembangan Anak. eJournal Ilmiah WIDYA, Volume 2. Nomor 2. ISSN 2337-6686. Halaman 920.http:// e-journal. jurwidyakop3.com/index.php/jurnalilmiah/article/view/177.

Winarsih, B. D. (2012). Pengaruh Peran Serta Orangtua dengan Dampak Hospitalisasi pada Anak Usia Prasekolah di RSUD RA Kartini Jepara. Fakultas Ilmu Keperawatan Program Studi Magister Ilmu Keperawatan, Depok.

Wong, D., L. (2000). Whaley and Wong's nursing care of infants and children. (7th ed.). St. Louis: Mosby. 